\title{
Stability relations of some titanium-minerals (sphene, perovskite, rutile, anatase)
}

\author{
R. D. SchüING and B. W. VINK \\ Vening Meinesz Laboratory of Geophysics and Geochemistry, Utrecht, \\ Holland
}

(Received 1 May 1967; accepted in revised form 18 July 1967)

Abstract-The equilibrium curve for the reaction:

$$
\text { calcite + quartz + anatase } \leftrightharpoons \text { sphene }+\mathrm{CO}_{2} \text {, }
$$

has been experimentally determined between 340 and $450^{\circ} \mathrm{C}$. Solubility measurements of rutile and anatese at temperatures of 200 and $300^{\circ} \mathrm{C}$ showed that the free energy of the reaction:

$$
\text { anatase } \rightarrow \text { rutile, }
$$

is of the order of -0.2 to $-0.3 \mathrm{kcal}$, which means that an equilibrium curve for the formation of sphene from calcite, quartz and rutile will be shifted only slightly towards higher temperatures or lower $\mathrm{CO}_{2}$-pressures relative to the same equilibrium with anatase instead of rutile. Experiments with perovskite and various silicates show that perovskite cannot stably coexist with quartz, enstatite, albite and sanidine, and thus is restricted to very silica-under-saturated rocks (carbonatites, ultramafic rocks and phonolitic extrusives). The value for the free energy of the reaction:

$$
\text { perovskite }+ \text { quartz } \rightarrow \text { sphene }
$$

was found to be between -4.75 and $-8.6 \mathrm{kcal}$, which checks well with the calorimetrically determined value for this reaction of $-7.05 \mathrm{kcal}$ (TODD and KELLEY, 1956).

As sphene in almost all cases seems to be stable under natural conditions relative to the association rutile + quartz + calcite, this sets rather severe upper limits to the $\mathrm{CO}_{2}$-pressures which can be reached in nature during epizonal metamorphism.

\section{INTRODUCTION}

The investigations can be divided into three parts:

1. Experiments.

2. Thermodynamic considerations.

3. Application to natural occurrences.

The experiments were carried out partly at the Dept. of Geology, Princeton University, and partly at the Vening Meinesz Laboratory of Geophysics and Geochemistry of the Utrecht University.

The reaction products were always identified by $\mathrm{X}$-ray diffractometry; the presence of small amounts of calcite was verified under the binocular microscope by the evolution of $\mathrm{CO}_{2}$ in the powder on addition of a drop dilute $\mathrm{HCl}$. Further details are given below.

\section{EXPERIMENTS}

\section{A. Determination of the sphene equilibrium curve}

The bombs which the Department of Geology, Princeton University, kindly put at the disposal of the senior author, had a limited temperature range. At temperatures higher than 
$440^{\circ} \mathrm{C}$ leaks occurred frequently. As it could be expected that reaction rates would be slow for the reaction:

$$
\underset{\text { (calcite) }}{\mathrm{CaCO}_{3}}+\underset{\text { (quartz) }}{\mathrm{SiO}_{2}}+\underset{\text { (anatase) }}{\mathrm{TiO}_{2}} \leftrightharpoons \underset{\text { (sphene) }}{\mathrm{CaTiSiO}_{5}}+\mathrm{CO}_{2}
$$

at temperatures below $450^{\circ} \mathrm{C}$, it was decided from the beginning to use an unconventional technique for the determination of this equilibrium. The $50 \mathrm{ml}$ bombs (Autoclave AG series) were provided with platinum liners; these were loaded completely with a stoichiometric mixture of calcito + quartz + anatase $(45 \mathrm{~g})$ to whioh $10 \mathrm{ml}$ of a $1 \mathrm{~N} \mathrm{NaCl}$-solution was added. NaClsolutions were used instead of distilled water as it was supposed that reaction rates would be enhanced by the addition of $\mathrm{NaCl}$. The bombs were then lowered into pre-heated deep furnaces and brought to the desired temperature. The bombs were continuously connected with Helicoid pressure gauges through a pressure capillary.

By plotting temperature against pressure during the heating period, it was determined that the amount of reaction taking place during the heating period was essentially negligible or only very slight at the higher temperatures. Therefore a "base-pressure" of water vapour pressure only could be established at the start of each run. Thereafter the course of the reaction could be followed by plotting the pressure against time for reaction times varying from 1 day to several months (Fig. 1 and Table 1).

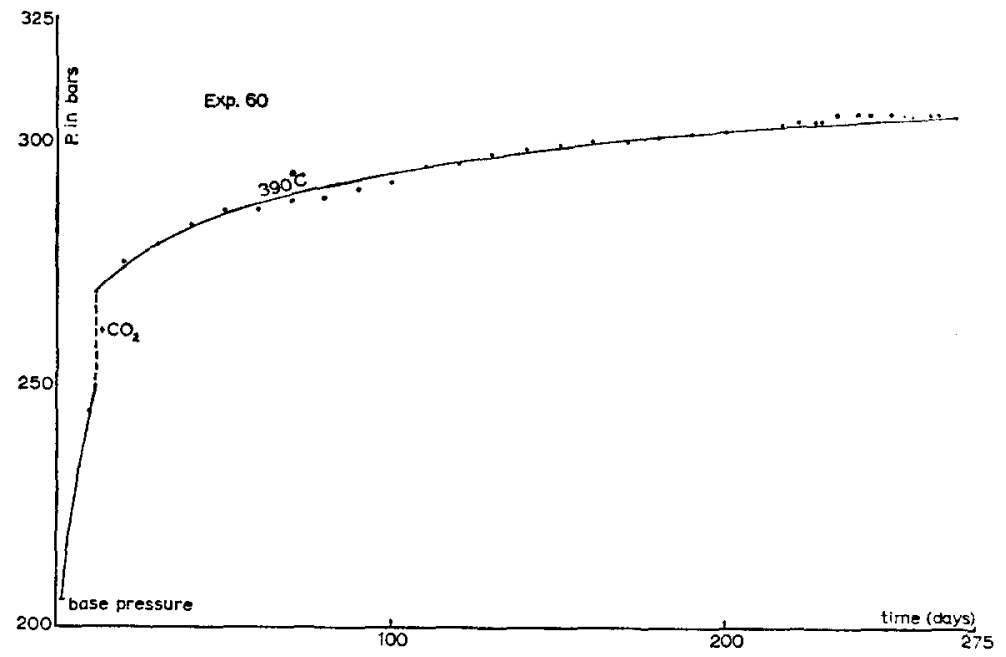

Fig. 1. Example of pressure-time curve for the reaction calcite + quartz + anatase $\leftrightharpoons$ sphene $+\mathrm{CO}_{2}$.

At higher temperatures after a few hours or days some extra $\mathrm{CO}_{2}$ was pumped into the pressure vessels (but still well below the expected equilibrium pressure) so that the reaction would not halt because the starting products would be completely consumed. Most runs stopped due to breakdown of the pressure connections or leaks at the copper washer. Equilibrium pressures were deduced by extrapolation of the pressure-time curves to infinite time. This extrapolation was done graphically by considering the maxinum and minimum pressures which different smooth concave curves could possibly reach before becoming essentially horizontal. The uncertainty of this extrapolation and the instrumental errors together make up the uncertainty in the determination of the equilibrium fugacities (Fig. 2). That the valuos thus determined are equilibrium fugacities and not just rate points is further indicated by the fact that the values plot on a straight line on a $\ln f-1 / T$-plot, and that at only slightly higher $\mathrm{CO}_{2}$-pressures reversals of the reaction have been obtained. Table $\mathrm{I}$ gives the essential data of the runs by which the equilibrium curve was determined. The temperature was recorded every 2 min by a monitor, and showed generally less than $\pm 2^{\circ} \mathrm{C}$ variation. The monitor was not 
Table 1. Equilibrium $\mathrm{CO}_{2}$-pressures and fugacities as deduced from pressuretime experiments, with stoichiometric mixtures of calcite + quartz + anatase, in a 1 mol.NaCl-solution

\begin{tabular}{ccccc}
\hline Run No. & Temp. $\left({ }^{\circ} \mathrm{C}\right)$ & Time (days) & $\begin{array}{c}\text { Extrapolated } \\
\mathrm{CO}_{\mathbf{2}} \text {-pressures }\end{array}$ & $\begin{array}{c}\text { Equivalent } \\
\text { CO }_{2} \text {-fugacities }\end{array}$ \\
\hline 70 & 340 & 124 & $46 \cdot 2 \pm 9$ bars & $\mathbf{4 6 \cdot 5}$ \\
$\mathbf{5 7}$ & $\mathbf{3 6 0}$ & $\mathbf{5 9}$ & $\mathbf{6 7} \cdot 5 \pm 10$ bars & $\mathbf{6 9}$ \\
11 & 380 & 15 & $83 \pm 10$ bars & 85 \\
49 & 385 & 8 & $98 \pm 10$ bars & 102 \\
60 & 390 & 261 & $101 \pm 6$ bars & 104 \\
10 & 400 & 16 & $110 \pm 12$ bars & 113 \\
62 & 410 & 25 & $140 \pm 15$ bars & 145 \\
54 & 415 & 6 & $138 \pm 15$ bars & 143 \\
14 & 427 & 15 & $155 \pm 20$ bars & 162 \\
52 & 440 & 4 & $203 \pm 15$ bars & 210 \\
56 & 440 & 4 & $190 \pm 15$ bars & 197 \\
59 & 445 & 7 & $221 \pm 15$ bars & 250 \\
73 & 450 & 1 & $228 \pm 28$ bars & 260 \\
\hline
\end{tabular}

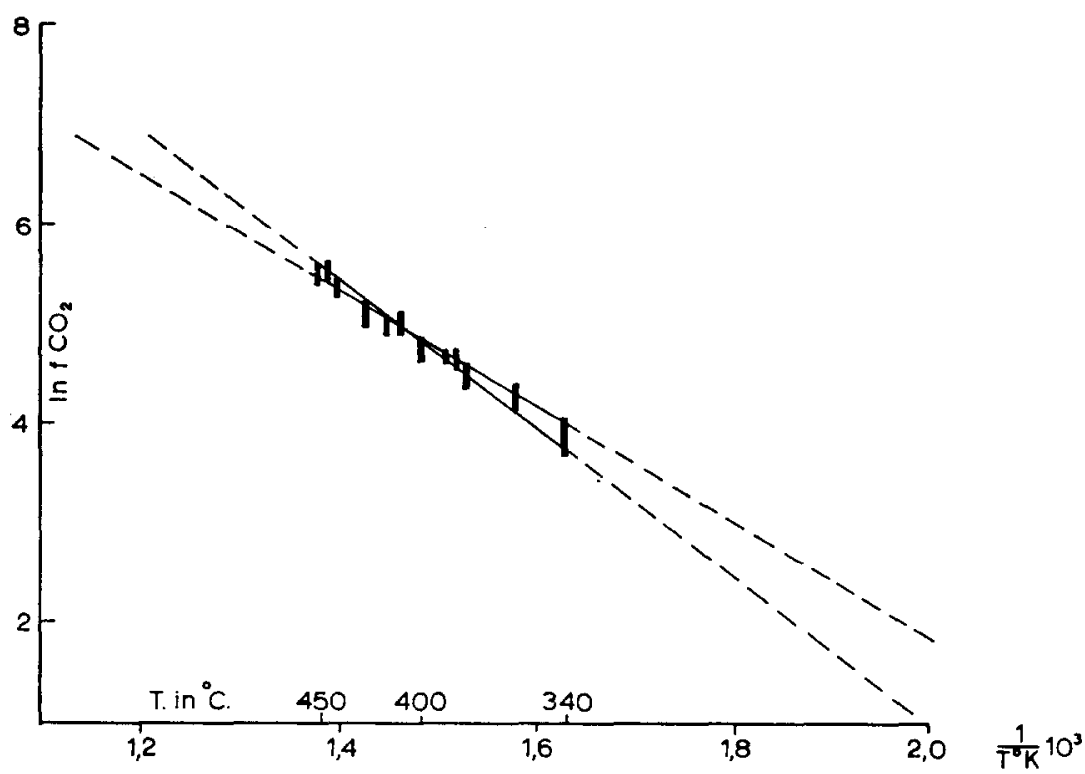

Fig. 2. Results of the experiments on the sphene equilibrium. The size of the rectangles indicates the uncertainty, caused by the extrapolation of the pressuretime curves (Fig. 1), as well as the experimental error.

calibrated for this series of experiments. In all runs it was verified that at the end calcite, quartz, anatase and sphene were all present. In an equilibrium situation the presence of all four solid phuses ut a fixed temperature would fix the $\mathrm{CO}_{2}$-fugacity.

Anatase was chosen as a starting product instead of rutile, as this was the form of chemically pure $\mathrm{TiO}_{2}$ available, and furthermore, it was hoped that the (metastable) anatase would react quicker while at the same time converting into rutile in tho hydrothormal runs. This was never the case. Anatase only converted measurably into rutile when rutile was added as seeds. This was not done in the runs which were used for the determination of the equilibrium curve which 
therefore applies to the reaction with anatese only. In a few runs the reaction was reversed by putting sphene powder under $\mathrm{CO}_{2}$-pressures higher than the deduced equilibrium $\mathrm{CO}_{2}$-pressure for that particular temperature. Although the reversed reaction was slow, and much less than half of the charge had reacted even after some weeks, a reversal could be clearly established (runs 69, 74 in which all three, and runs $19,47,75,40,43$ and 50 in which only two of the three products could be identified-Table 2). Even in these runs it was anatase, and not rutile, that formed from the breakdown of sphene.

Table 2. List of runs in which the sphene equilibrium was reversed or in whioh reversal was indicated by the presence of 2 out of 3 breakdown phases of sphene (calcite, quartz, anatase) in small amounts in the reaction products.

Identification of phases enclosed in parenthesis is doubtful

\begin{tabular}{|c|c|c|c|c|c|}
\hline $\begin{array}{l}\text { Run } \\
\text { No. }\end{array}$ & Temp. & $\begin{array}{l}\text { Time } \\
\text { (days) }\end{array}$ & $\begin{array}{l}\text { Starting } \\
\text { material }\end{array}$ & $\mathrm{CO}_{2}$-pressures & Products \\
\hline 19 & 320 & 14 & Sphene & 138 bars & $\begin{array}{l}\text { Sphene, calcite, anatase, } \\
\text { (quartz), (rutile), } \\
\text { (perovskite) }\end{array}$ \\
\hline 47 & 360 & 18 & Sphene & 124 bars & Anatase, calcite, sphene \\
\hline 69 & 350 & 15 & Sphene & 160 bars & $\begin{array}{l}\text { Sphene, quartz, anatase, } \\
\text { calcite }\end{array}$ \\
\hline 74 & 355 & 33 & Sphene & 177 bars & $\begin{array}{l}\text { Sphene, quartz, calcite, } \\
\text { anatase }\end{array}$ \\
\hline 75 & 370 & & $\begin{array}{c}\text { Sphene (on } \\
\text { Cu-wire) }\end{array}$ & 197 bars & $\begin{array}{l}\text { Sphene, anatase, quartz, } \\
\text { (Cu-carbonate) }\end{array}$ \\
\hline 40 & 340 & 16 & Sphene & 255 bars & Sphene, anatase, calcite \\
\hline 43 & 355 & 18 & Sphene & & Sphene, anatase, calcite \\
\hline 50 & 380 & 18 & Sphene & & Sphene, trace anatase \\
\hline
\end{tabular}

The difference between the extrapolated pressure which the system would reach at infinite time and the base-pressure is considered to be the equilibrium $\mathrm{CO}_{2}$-pressure of the reaction at the temperature of the run. From this pressure an equilibrium fugacity can be determined with. the aid of conversion tables (MAJUMdar and RoY, 1956); these calculated fugacities are ulso given in Table 1 .

\section{B. Solubility measurements of anatase and rutile}

In order to use experimental data on the metastable equilibrium curve involving quartz, calcite and anatase for a calculation of the stable equilibrium curve involving quartz, calcite and rutile, the free energy of the reaction:

$$
\text { anatase } \rightarrow \text { rutile }
$$

must be known. A value can be found in JANAF's (1960) thermochemical data, to which Dr. R. A. RoBre kindly drew our attention. This value of the order of $-7 \cdot 4 \mathrm{kcal}$ must clearly be too high by probably an order of magnitude as otherwise one can calculate that rutile + quartz + calcite should be an extremely stable essociation, reacting to form sphene only at temperatures well above the equilibrium curve of wollastonite.

As it is clear from petrologic experience that sphene forms much earlier in a metamorphic sequence than wollastonite, the existing thermochemical data seem suspect. It was decided therefore to carry out some solubility measurements of the two $\mathrm{TiO}_{2}$-polymorphs at different temperatures. The bombs were fitted with an extra valve which connected with a silver tube extending down through the solution, and through which samples of solution could be taken at constant temperature and at constant pressure. These solutions were collected through a filter in a pre-weighed amount of dilute $\mathrm{HCl}$ to prevent precipitation of $\mathrm{TiO}_{2}$ during cooling. The solutions were analysed by the Tiron method (Swerc, 1959) in a Beckman colorimeter. 
Table 3. Solubility of anatase (run 72) and of rutile (run 77) at temperatures of 200 and $300^{\circ} \mathrm{C}$, in a 1 mol.NaCl-solution, under its own vapour pressure

\begin{tabular}{|c|c|c|c|c|}
\hline Run No. & Temp $\left({ }^{\circ} \mathbf{C}\right)$ & $\operatorname{Time}(h r)$ & Solubility in & n ppm $\mathrm{Ti}$ \\
\hline $72-1$ & 200 & 20 & \multirow{2}{*}{1.68} & \multirow{4}{*}{ anatase } \\
\hline $72-2$ & 200 & 115 & & \\
\hline $72-3$ & 300 & 72 & $2.02\}_{2}$ & \\
\hline $72-4$ & 300 & 315 & $2 \cdot 13\}^{2 \cdot 07}$ & \\
\hline $77-1$ & 200 & 72 & 1.55 & \multirow{5}{*}{ rutile } \\
\hline $77-2$ & 200 & 115 & $1.11\} 1.33$ & \\
\hline $77-3$ & 300 & 12 & \multirow{2}{*}{$1 \cdot 57\}$} & \\
\hline $77-4$ & 300 & 72 & & \\
\hline $77-5$ & 300 & 552 & $1 \cdot 39$ & \\
\hline
\end{tabular}

The analytical data are given in Table 3. Although the amounts of $\mathrm{TiO}_{2}$ in solution are small, and relative errors therefore large, a systematic but small difference of the solubility of anatase vs. rutile is apparent. As the rutile was prepared from the anatase by prolonged heating above $1000^{\circ} \mathrm{C}$, there was no chemical difference between the two modifications.

\section{Perovskite-silicate reactions}

These experiments were carried out in the Vening Meinesz Laboratory in cold-seal bombs. The reactants, to which $10 \mathrm{mg} \mathrm{H}_{2} \mathrm{O}$ was added, were enclosed in welded gold capsules. The reaction products were identified by $\mathrm{X}$-ray powder diagrams, taken with a Nonius camera which permits the simultaneous photography of four samples.

All experiments were carried out under 1000 bars water pressure, in sealed collapsible goldcapsules. Temperatures were between 600 and $800^{\circ} \mathrm{C}$ (se日 Table 6) and the duration of the runs was generally three weeks. The principle of the determination of $\Delta G$ of the reaction:

$$
\mathrm{CaTiO}_{3}+\mathrm{SiO}_{2} \rightarrow \mathrm{CaTiSiO}_{5},
$$

was to see from which silica-saturated silicates $\mathrm{CaTiO}_{3}$ is capable of removing $\mathrm{SiO}_{2}$ to form sphene, and conversely, which undersaturated silicates (or oxides) will react with sphene to form perovskite. Further details are given under the heading "THERMOD YNAMrCaL Considerations", part C (below).

\section{Thermodynamical Considerations}

A. Calculation of the equilibrium curve for the reaction:

$$
\mathrm{CaCO}_{3}+\mathrm{SiO}_{2}+\mathrm{TiO}_{2} \rightleftharpoons \mathrm{CaTiSiO}_{5}+\mathrm{CO}_{2}
$$

The most direct way to calculate the equilibrium curve is by means of the formula:

$$
\Delta G_{T}{ }^{r}=-R T \ln k_{T}
$$

The equilibrium constant for this reaction being equal to the $\mathrm{CO}_{2}$-fugacity, the formula is written:

in which:

$$
\ln f_{\mathrm{Co}_{2}}=\frac{-\Delta G_{T}{ }^{r}}{R T}
$$

$$
\Delta G_{T^{r}}=\Delta H_{298}^{r}+\int_{298}^{T} \Delta c_{p} \mathrm{~d} T-(298+\Delta T) \cdot\left(\Delta s_{298}+\int_{298}^{T} \frac{\Delta c_{p}}{T} \mathrm{~d} T\right) .
$$


(2) and (3) combined

$$
\ln f_{\mathrm{CO}_{2}}=\frac{-\Delta G_{298}^{r}+\Delta T \cdot \Delta s_{298}-\Delta\left(H_{T}-H_{298}\right)+T \cdot \Delta\left(s_{T}-s_{298}\right)}{R T} .
$$

As the standard free energies of formation of sphene and calcite are given (from the oxides), $\Delta G_{298}^{r}$ can be calculated and turns out to be +4560 cal. The influence of the pressure on the solid phases has bcen neglected in these formulas. As wo have restricted our considerations to pressures less than 1000 bars, the error thus introduced is less than $0.5 \mathrm{kcal} . \Delta s_{298}=37.83 \mathrm{cal} / \mathrm{deg} \mathrm{mol}$ (taking rutile as the $\mathrm{TiO}_{2}$-polymorph). The values of $H_{T}-H_{298}$ and $s_{T}-s_{298}$ are tabulated (KELLEY, 1960) for all constituents of the reaction.

As all terms in the right hand side of formula (4) are known, $\mathrm{CO}_{2}$-fugacities can be calculated for a number of temperatures (Table 4, column E). The calculated reaction between $\ln f_{\mathrm{CO}_{2}}$ and $1 / T$ has been plotted in Fig. 3. As the experimental data are not in agreement with the calculated curve, this has been calculated in

Table 4. Equilibrium fugacities at different temperatures for the wollastonite equilibrium curve and the sphene equilibrium curve.

Fugacities are given in bars

\begin{tabular}{|c|c|c|c|c|c|c|}
\hline \multirow{2}{*}{ Temp $\left({ }^{\circ} \mathrm{K}\right)$} & A & B & C & D & $\mathbf{E}$ & $\mathbf{F}$ \\
\hline & $f_{\mathrm{OO}_{2}}^{a}$ (DAN.) & $f_{\mathrm{CO}_{2}}^{a}$ (HARKER) & $f_{\mathrm{CO}_{2}}^{c}$ (DAN.) & $f_{\mathrm{CO}_{2}}^{c}$ (HARKER) & $f_{\mathrm{CO}_{2}}^{c}$ (calc.) & $f_{\mathrm{OO}_{2}}^{c}$ (exp.) \\
\hline 298 & $10^{-7}$ & $10^{-11}$ & $8 \cdot 6 \cdot 10^{-4}$ & $0 \cdot 8 \cdot 10^{-6}$ & $4 \cdot 8 \cdot 10^{-4}$ & - \\
\hline 400 & $10^{-3.1}$ & $10^{-6}$ & 0.76 & $0 \cdot 8 \cdot 10^{-3}$ & 0.4 & 一 \\
\hline 500 & $10^{-0.8}$ & $1 \cdot 6 \cdot 10^{-3}$ & 29 & 0.3 & $19 \cdot 1$ & $2 \cdot 7-6$ \\
\hline 553 & 1 & $2 \cdot 5 \cdot 10^{-2}$ & 103 & $2 \cdot 5$ & 80 & $11 \cdot 5-20$ \\
\hline 600 & $4 \cdot 4$ & 0.2 & 295 & 11 & 232 & $30-42 \cdot 5$ \\
\hline 633 & 10 & $0 \cdot 6$ & 525 & 32 & 435 & $60-74$ \\
\hline 700 & 50 & 6 & 1710 & 190 & 1290 & $172-190$ \\
\hline 738 & 100 & 15 & 2750 & 430 & 2200 & $270-330$ \\
\hline 800 & 290 & 66 & 5850 & 1300 & 4570 & $494-700$ \\
\hline 873 & 810 & 332 & 11880 & 4900 & 9330 & $870-1400$ \\
\hline 933 & & 1090 & & 11750 & & \\
\hline 973 & & 1940 & & 20150 & & \\
\hline
\end{tabular}

Uolumn A. Calculated values for the wollastonite equilibrium curve by DANIELSSON (1950).

Column B. Experimental data from HARKer and Tutrue (1956); the data, except the last three, are extrapolated from a $\log f_{\mathrm{co}_{2}}-(1 / T) \cdot 10^{3}-$ diagram.

Column C. Fugacities of the sphene equilibrium curve, calculated with formula (9), using the calculated data of DanIELSSON (1950) of the wollastonite curve.

Column D. Fugacities of the sphene equilibrium curve, calculated with formula (9), using the values from the wollastonite curve, extrapolated from experimental data from HARKER and TUTTLE (1956).

Column E. Fugacities of the sphene equilibrium curve, calculated by means of the formula $\Delta G_{T}{ }^{r}=-R T \ln k_{r}$.

Column F. Direct experimental data of the sphene equilibrium curve (this paper), with data extrapolated from a $\ln f_{\mathrm{CO}_{3}}-(1 / T) \cdot 10^{3}$ diagram.

To obtain the calculated fugacities of the columns $\mathrm{C}, \mathrm{D}$ and $\mathrm{E}$, rutile is used as $\mathrm{TiO}_{2}-$ polymorph. In the experiments (column $\mathrm{F}$ ) anatase was the $\mathrm{TiO}_{2}$-modification. (See also part $\mathrm{B}$ of Thermodynamicax Considerations, (in text), for the reaction anatase $\rightarrow$ rutile). 
another way, starting from the known equilibrium curve of the reaction:

$$
\mathrm{CaCO}_{3}+\mathrm{SiO}_{2} \rightleftharpoons \mathrm{CaSiO}_{3}+\mathrm{CO}_{2} .
$$

For this curve too, calculation and experiment are not in agreement; the $\mathrm{CO}_{2^{-}}$ fugacities at equilibrium as calculated by DANIELSSON (1950) are much higher than the experimentally determined values of HARKER and TuTTLE (1956). A similar discrepancy is found between the calculated $\mathrm{CO}_{2}$-fugacities of the sphene equilibrium

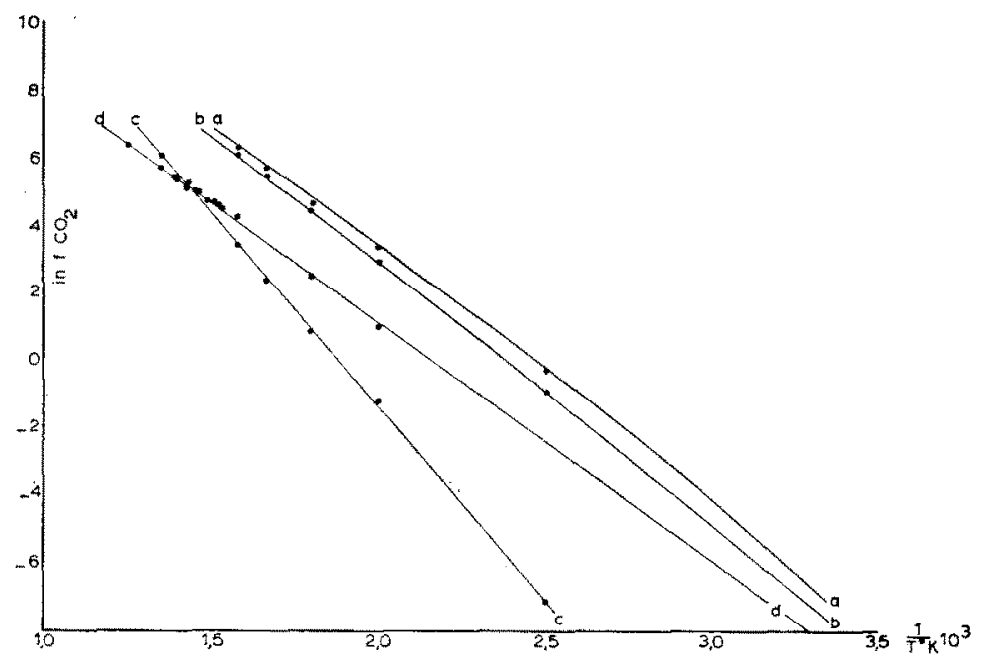

Fig. 3. Equilibrium curves for the sphene equilibrium:

aa. Calculated, using the calculated wollastonite equilibrium data (DANIEIsson, $1950)$.

bb. Calculated from $\Delta G=-R T \ln k$.

cc. Calculated, using the experimental data on the wollastonite equilibrium (Harker and Tuttre, 1956).

dd. Experimental curve, with extrapolated values (this work).

and the experimental values. The calculated fugacities given in Column $\mathrm{E}$ of Table 4 are higher by a factor of about three than the values determined experimentally.

It seems likely that these discrepancies are due to inaccuracy of the listed thermodynamical data of the minerals involved.

In order to find another method to calculate the sphene equilibrium curve, we can consider the following reactions:

(a) $\mathrm{CaCO}_{3}+\mathrm{SiO}_{2} \rightleftharpoons \mathrm{CaSiO}_{3}+\mathrm{CO}_{2}$

(b) $\mathrm{CaSiO}_{3}+\mathrm{TiO}_{2} \rightarrow \mathrm{CaTiSiO}_{5}$

(c) $\mathrm{CaCO}_{3}+\mathrm{SiO}_{2}+\mathrm{TiO}_{2} \rightleftharpoons \mathrm{CaTiSiO}_{5}+\mathrm{CO}_{2}$

From the reaction (a) is known the $f_{\mathrm{CO}_{2}}-T$ equilibrium curve, as determined experimentally by Harker and TuTtue (1956), and as calculated by DaNinLsson (1950). From reaction (b) the heat and free energy of reaction at all temperatures are known (TodD and KeldeY, 1956). 
The following relation holds:

$$
\Delta G_{T}{ }^{r}(\mathrm{c})=\Delta G_{T}{ }^{r}(\mathrm{a})+\Delta G_{T}{ }^{r}(\mathrm{~b}) .
$$

At temperature $T_{x}$ and $\mathrm{CO}_{2}$-pressure $P_{x}$, we have at equilibrium:

$$
\Delta G_{0}{ }^{r}\left(T_{x}, P_{x}\right)=0 .
$$

Relation (5) can be applied at all temperatures and pressures:

$$
\Delta G_{a}{ }^{r}\left(P=1, T_{x}\right)=\Delta G_{a}{ }^{r}\left(P=1, T_{x}\right)+\Delta G_{b}{ }^{r}\left(P=1, T_{x}\right) .
$$

If the volume difference between the solid phases $\Delta V_{8, T_{x}}$ is neglected as it is small as compared to the volume of the $\mathrm{CO}_{2}$-gas, -in any case at pressures less than 1000 bars-, we can write at equilibrium:

$$
\Delta G_{c}{ }^{r}\left(T_{x}, P_{x}\right)=\Delta G_{a}{ }^{r}\left(P=1, T_{x}\right)+\Delta G_{b}{ }^{r}\left(P=1, T_{x}\right)+R T_{x} \cdot \ln \frac{f_{P_{x}}{ }^{c}}{f_{P=1}^{c}}=0 .
$$

Neglecting the volume change of the solid phases, we can write for reaction (a):

$$
\Delta G_{a}{ }^{r}\left(P=1, T_{x}\right)=-R T_{x} \cdot \ln \frac{f_{P_{x}}{ }^{a}}{f_{P=1}^{a}} .
$$

For reaction (b) the heat and free energy of reaction at all temperatures is given (TODD and KELLEY, 1956).

A combination of the formulas (7) and (8) yields:

$$
-R T_{x} \ln \frac{f_{P_{x}}{ }^{a}}{f_{P=1}^{a}}+\Delta G_{b}{ }^{r}\left(P=1, T_{x}\right)+R T_{x} \ln \frac{f_{P_{x}}{ }^{a}}{f_{P=1}^{a}}=0 .
$$

As at low pressures $(P=1)$ pressure and fugacity are equal for the reactions (a) and (c), the relation $f_{P=1}^{a}=f_{P=1}^{c}$ holds, so that the foregoing expression reduces to:

$$
\ln \frac{f_{P_{x}{ }^{0}}}{f_{P_{x}}{ }^{a}}=\frac{-\Delta G_{b}{ }^{r}\left(P=1, T_{x}\right)}{R T_{x}}
$$

By means of formula (9) the sphene equilibrium curve can be calculated by considering different values for $T_{x}$, for which temperature the corresponding $f_{P_{x}}{ }^{a}$ can be found on the known equilibrium curve of reaction (a). As all data of reaction (b) are given (ToDD and KELLEY, 1956), the unknown ${f_{P_{x}}}^{c}$ of the sphene equilibrium curve can be found for different values of $T_{x}$.

Some $\mathrm{CO}_{2}$-fugacities at equilibrium at different temperatures for reaction (a) are given in column A of Table 4 (calculated by DANIELSson, 1950) and in column B of Table 4 (experimental values of HARKER and TUTTLE, 1956). The corresponding $\mathrm{CO}_{2}$-fugacities of the sphene equilibrium curve are found in columns $\mathrm{C}$ and $\mathrm{D}$ of Table 4.

Because Tomn and $\mathrm{Katm}$ in (1956) use rutile as the $\mathrm{TiO}_{2}$-modification in their measurements of $\Delta H$ and $\Delta G$ of the reaction (b), the $\mathrm{CO}_{2}$-fugacities in columns $\mathrm{C}$ and $\mathrm{D}$ of Table 4 refer to the sphene equilibrium curve with rutile as the $\mathrm{TiO}_{2}$ polymorph.

From a consideration of columns C, D, E and F of Table 4 it can be concluded 
that a similar discrepancy between calculation and experiment shows up for the sphene equilibrium curve as had been found for the wollastonite equilibrium. Using the tabulated entropies and free energies, the $\mathrm{CO}_{2}$-fugacities of the sphene equilibrium curve become much higher than the experimentally determined values (Table 4, columns E and F). Using the data from Danielsson (1950) for the wollastonite equilibrium curve (thus using indirectly the tabulated standard free energies and entropies), the calculated $\mathrm{CO}_{2}$-fugacities of the sphene equilibrium curve become also much higher than the values determined experimentally (Table 4, columns $\mathrm{C}$ and F). Starting however with the experimental data for the wollastonite curve (HARKER and TUTTLE, 1956) the calculated $\mathrm{CO}_{2}$-fugacities are in reasonably good agreement with the experiments (Table 4, columns D and F).

\section{B. Free energy of the reaction; anatase $\rightarrow$ rutile}

The only data in the literature on the free energy of anatase are found in J ANAF's (1960) thermochemical tables. The source of these data is an unpublished ONRreport by Rossini et al. From these data a free energy of the reaction:

$$
\text { anatase } \rightarrow \text { rutile, }
$$

under standard conditions turns out to be $-7 \cdot 4 \mathrm{kcal}$, and as the entropy of reaction is very small, the same free energy of reaction is found at $700^{\circ} \mathrm{K}$. These data must be viewed with suspicion; from the fact that sphene has been broken down into calcite, quartz and anatase at $\mathrm{CO}_{2}$-pressures only slightly above the inferred equilibrium $\mathrm{CO}_{2}$-pressures it is apparent that the equilibrium curve for the reaction:

$$
\text { calcite + quartz + anatase } \leftrightharpoons \text { sphene }+\mathrm{CO}_{2} \text {, }
$$

is approximately right. It may not be located lower than the experimentally determined $\mathrm{CO}_{2}$-pressures which the reactants had built up during reaction. If one would now add a free energy of the reaction anatase $\rightarrow$ rutile of $-7 \cdot 4 \mathrm{kcal}$, this would make the association quartz + rutile + calcite extremely stable. For a $\mathrm{CO}_{2}$-pressure of 100 bars the sphene reaction with rutile instead of anatase would be shifted by $200^{\circ}$ towards higher temperatures, i.e. well above the equilibrium temperature of wollastonite at the same pressure. In fact sphene would form only at higher temperatures and/or lower $\mathrm{CO}_{2}$-pressures than does wollastonite from calcite + quartz, which is clearly contradicted by geological evidence. As we are only interested in the free energy difference between anatase and rutile, some solubility measurements of anatase and rutile were carried out. The data are given in Table 3.

Without knowing in what form $\mathrm{TiO}_{2}$ is present in solution, we can use these data to calculate a free energy of reaction for anatase $\rightarrow$ rutile.

For the reaction:

$$
\mathrm{TiO}_{2} \text { (anatase) } \rightarrow \mathrm{Ti} \text { (species in solution), }
$$

we can write

$$
\Delta G_{1}=G_{(\mathrm{Ti} \text {-spec, in sol. })}-G_{(\mathrm{an})} .
$$

The same can be done for the solution of rutile:

$$
\Delta G_{2}=G_{(\text {Ti-spec. in sol. })}-G_{(\text {rut })} .
$$


Provided that at the same temperature the Ti-species in solution produced by the solution of anatase and of rutile will be the same, it follows that:

As on the other hand:

$$
\Delta G_{3}=G_{(\mathrm{rut})}-G_{(\mathrm{an})}=\Delta G_{1}-\Delta G_{2} .
$$

and similarly:

$$
\Delta G_{1}=-R T \ln k_{1}=-R T \ln (\text { total } \mathrm{Ti} \text { in sol. })_{\mathrm{an}},
$$

it follows that:

$$
\Delta G_{2}=-R T \ln k_{2}=-R T \ln (\text { total Ti in sol.) })_{\text {rut }},
$$

$$
\Delta G_{3}=-R T\left(\ln k_{1}-\ln k_{2}\right) .
$$

Using the values of Table 3 we arrive at a free energy of reaction of -221 cal at $200^{\circ} \mathrm{C}$ and of $-316 \mathrm{cal}$ at $300^{\circ} \mathrm{C}$. Considering that there is a considerable uncertainty in the determination of the solubilities, we may say that the free energy of the reaction anatase $\rightarrow$ rutile will be $-0 \cdot 25 \pm 0 \cdot 2 \mathrm{kcal}$, with only a slight variation with temperature. As this value is compatible with geological evidence, the value of $-7.4 \mathrm{kcal}$ must be rejected, as being wholly outside the possible range. If the value of $-0.25 \mathrm{kcal}$ is accepted, it follows that the stable equilibrium curve for the sphene reaction from calcite + quartz + rutile will shift only to slightly lower $\mathrm{CO}_{2}$-pressures or slightly higher temperatures relative to the experimentally determined (metastable) equilibrium curve with anatase instead of rutile. This shift amounts to minus 30 bars (from 180 to 150 ) at a temperature of $700^{\circ} \mathrm{K}$.

\section{The free energy of the reaction; $\mathrm{CaTiO}_{3}+\mathrm{SiO}_{2} \rightarrow \mathrm{CaTiSiO}_{5}$}

In Table 5 some reactions between undersaturated silicates or oxides and $\mathrm{SiO}_{2}$ are listed with their free energy of reaction at $298^{\circ} \mathrm{K}$ and $973^{\circ} \mathrm{K}$. In order to deter-

\begin{tabular}{|c|c|c|c|}
\hline & & $\Delta G_{298^{\circ} \mathrm{K}, 1 \mathrm{bar}}^{\tau}$ & $\Delta G_{\mathbf{9 7 3}{ }^{\circ} \mathrm{K}, 1 \mathrm{bar}}$ \\
\hline $\begin{array}{l}\mathrm{Mg}_{2} \mathrm{SiO}_{4} \\
\frac{1}{2} \mathrm{NaAlSiO}_{4} \\
\mathrm{KAlSi}_{2} \mathrm{O}_{6} \\
2 \mathrm{ZnO} \\
2 \mathrm{MgO}\end{array}$ & $\begin{array}{l}+\mathrm{SiO}_{2} \rightarrow 2 \mathrm{MgSiO}_{3} \\
+\mathrm{SiO}_{2} \rightarrow \frac{1}{2} \mathrm{NaAlSi}_{3} \mathrm{O}_{8} \\
+\mathrm{SiO}_{2} \rightarrow \mathrm{KAlSi}_{3} \mathrm{O}_{8} \\
+\mathrm{SiO}_{2} \rightarrow \mathrm{Zn}_{2} \mathrm{SiO}_{4} \\
+\mathrm{SiO}_{2} \rightarrow \mathrm{Mg}_{2} \mathrm{SiO}_{4}\end{array}$ & $\begin{array}{l}-2 \cdot 2 \\
-2 \cdot 6 \\
-4 \cdot 8 \\
-7 \cdot 2 \\
-15 \cdot 1\end{array}$ & $\begin{array}{l}-2 \cdot 1 \\
-2 \cdot 85 \\
-3 \cdot 8 \\
-7 \cdot 6 \\
-15 \cdot 1\end{array}$ \\
\hline
\end{tabular}
mine the free energy of formation of sphene from perovskite + quartz, mixtures of

Table 5. Free energies of some reactions between undersaturated silicate, or oxide, and quartz, (in keal), at $298^{\circ}$ and $973^{\circ} \mathrm{K}$

perovskite with the saturated silicates at the right hand side of the reactions of Table 5 were treated hydrothermally at temperatures around $700^{\circ} \mathrm{C}$. The results of these runs are listed in Table 6. From this table it is apparent that perovskite can react with enstatite, albite and $\mathrm{K}$-feldspar, forming sphene and rospcctivcly forsterite, nepheline and leucite. With respect to willemite and forsterite however, perovskite is stable, and sphene reacts with periclase and zincite.

The equation:

$$
\Delta G_{T}{ }^{r}=\Delta H_{T}{ }^{r}-T \cdot \Delta s_{T},
$$


Table 6. List of runs of perovskite-silicate reactions

\begin{tabular}{|c|c|c|c|c|c|}
\hline Run No. & Temp. ${ }^{\circ} \mathrm{C}$ & Pressure & $\operatorname{Tim} \theta$ & Starting material & Products \\
\hline 105 al & $700^{\circ}$ & 1000 bars & 3 weeks & Enstatite + perovskite & Sphene + forsterite \\
\hline $105 \mathrm{a} 2$ & $700^{\circ}$ & 1000 bars & 3 weeks & Albite + perovskite & Sphene + nepheline \\
\hline $105 \mathrm{a} 3$ & $700^{\circ}$ & 1000 bars & 3 weeks & $\mathrm{K}$-feldspar + perovskite & Sphene + leucite \\
\hline 105 a5 & $700^{\circ}$ & 1000 bars & 3 weeks & Forsterite + perovskite & Forsterite + perovskite \\
\hline 170 al & $760^{\circ}$ & 1000 bars & 24 days & Willemite + perovskite & Willemite + perovskite \\
\hline 123 al & $670^{\circ}$ & 1000 bars & 15 days & Sphene + periclase & Forsterite + perovskite \\
\hline $170 \mathrm{a} 2$ & $760^{\circ}$ & 1000 bars & 24 days & Sphene + zincite & Willemite + perovskite \\
\hline
\end{tabular}

can be written as:

$$
\Delta G_{T}{ }^{r}=\Delta H_{298}^{r}+\int_{298}^{T} \Delta c_{p} \mathrm{~d} T-(298+\Delta T) \cdot\left(\Delta s_{298}+\int_{298}^{T} \frac{\Delta c_{p}}{T} \mathrm{~d} T\right) .
$$

Both corrections of $\Delta H$ and $\Delta s$ with $\Delta c_{p}$ can be neglected. For reactions between solid phases the role of pressure too can be neglected as the volume changes, and consequently the $P . \Delta v$-terms, are small, at least at the moderate pressures of 1000 bars of the runs described above (100 cal or loss). Introducing these simplifications, the above equation becomes:

$$
\Delta G_{T}{ }^{t}=\Delta G_{298}^{r}-\Delta T \cdot \Delta s_{298}
$$

Consider the following reactions at $973^{\circ} \mathrm{K}$ :

(1) $\mathrm{Mg}_{2} \mathrm{SiO}_{4}+\mathrm{SiO}_{2} \rightarrow 2 \mathrm{MgSiO}_{3}-2 \cdot 1 \mathrm{kcal}$

$\underline{\text { (2) } \mathrm{CaTiO}_{3}+2 \mathrm{MgSiO}_{3} \rightarrow \mathrm{CaTiSiO}_{5}+\mathrm{Mg}_{2} \mathrm{SiO}_{4}-a \mathrm{kcal}}+$

(3) $\mathrm{CaTiO}_{3}+\mathrm{SiO}_{2} \rightarrow \mathrm{CaTiSiO}_{5}+\Delta G_{973}^{r}$.

Because reaction (2) proceeds to the right, the free energy of reaction must be negative.

Thus:

$$
\Delta G_{973}^{r}(3)=\Delta G_{298}^{r}-675 . \Delta s_{298}<-2 \cdot 1 \mathrm{kcal}
$$

$\Delta s_{298}(3)$ being $-1.40 \mathrm{cal} / \mathrm{deg}$, it follows that $\Delta G_{298}^{r}(3)<-3.0 \mathrm{kcal}$. These same calculations can be applied to the perovskite-albite reaction, yields $\Delta G_{298}^{r}(3)<-3 \cdot 8$ kcal, and for the perovskite-K-feldspar reaction $\Delta G_{298}^{r}(3)<-4.75 \mathrm{kcal}$.

For the reactions in which spene reacts to form perovskite, a similar reasoning yields for the zincite-sphene reaction that $\Delta G_{298}^{r}(3)>-8.6 \mathrm{kcal}$, and for the periclase-sphene reaction that $\Delta G_{298}^{r}(3)>-16.0 \mathrm{kcal}$. So in reality it is the third and the fourth reactions of Table 5 which bracket (by means of runs No. 105 a3, and 170 a2 of 'Table 6 ) the free energy of the reaction perovskite + quartz to sphene. This free energy must be between -4.75 and $-8.6 \mathrm{kcal}$; the calorimetrically determined value of $-7.05 \mathrm{kcal}$, (TODD and KELLEY, 1956) falls within this range.

\section{Applications to Natural Occurrences}

The main application of the above experimental work on sphene is, in our opinion, the fact that the sphene equilibrium curve allows a delimitation of the maximum 
$\mathrm{CO}_{2}$-pressures that commonly occur in nature, at least for the lower grades of metamorphism (epi- and mesozone). As sphene seems to be nearly always stable and as we have sought in vain for associations of quartz, calcite and rutile/anatase in metamorphic rocks, the conclusion seems warranted that the $\mathrm{CO}_{2}$-pressures in nature rarely if ever exceed the $\mathrm{CO}_{2}$-pressures of the sphene equilibrium curve.* As on the other hand associations of quartz and calcite are exceedingly common

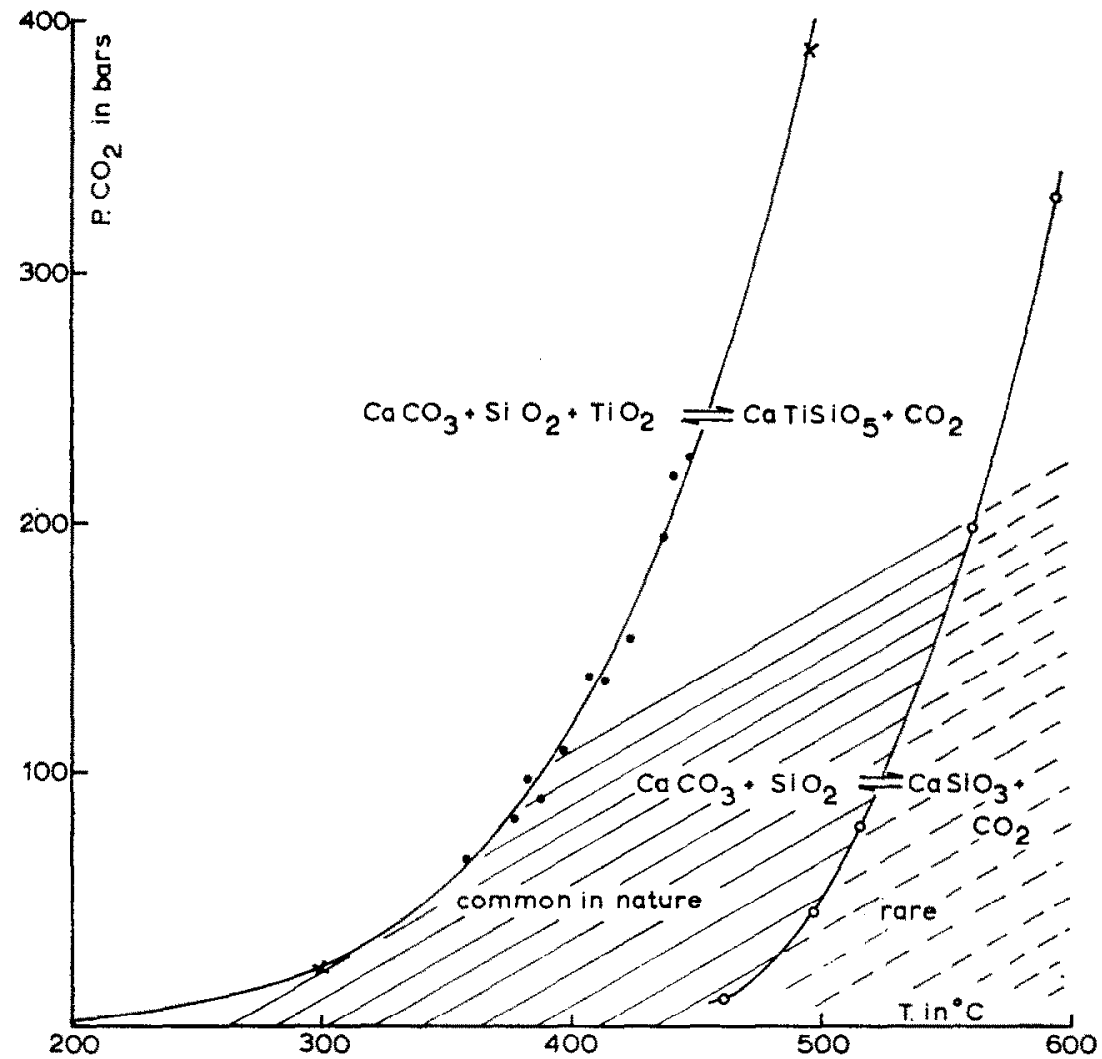

Fig. 4. The experimental sphene equilibrium curve (this paper) and the experimental curvo for the wollastonite equilibrium (HARker and TuTrLe, 1956), and the range of inferred $\mathrm{CO}_{2}$-pressures in nature, during epi- and mesozonal metamorphism.

very often in association with sphene, a field of normal $\mathrm{CO}_{2}$-pressures during metamorphism can be delineated, as has been done in Fig. 4. It seems likely that the $\mathrm{CO}_{2}$ partial pressures during metamorphism make up only a fraction of the total pressure, at least for the lower grades of metamorphism. $\left(<500^{\circ} \mathrm{C}\right.$. $)$

The maximum possible $\mathrm{CO}_{2}$-pressures for the sphene equilibrium curve at a temperature of $25^{\circ} \mathrm{C}$, as extrapolated from the experimental data, fall in the range near $10^{-2}$ to $10^{-3} \mathrm{~atm} \mathrm{CO}_{2}$-pressure. It follows therefore that authigenic formation

* Karpor (1966) observed the reaotion ealcite $\mid$ quartz $\mid$ rutile $\rightarrow$ apheno $+\mathrm{CO}_{2}$ in a marble complex of greenschist facies metamorphic grade. His calculated curve for this reaction is close to our calculated eurve of Fig. 3, bb. 
of sphene in soils and sediments cannot be ruled out as a possibility (MILnER, 1962).

The perovskite cannot crystallize in equilibrium with enstatite, albite or $\mathrm{K}$ feldspar, and its occurrence is therefore restricted to carbonatites, ultrabasic rocks and very undersaturated lavas, in which it occurs commonly (DEER et al., 1965).

The very near equality of the free energies of formation of the $\mathrm{TiO}_{2}$-polymorphs rutile and anatase, finally, which is indicated by the solubility-experiments, shows why anatase is so commonly formed, especially in low-temperature environments, instead of the stable polymorph rutile. High pressure will strongly favour the formation of rutile; therefore, it can be concluded that anatase has no true stability field.

Acknowledgements-The senior author wishes to thank the Netherlands Organization for the Advancement of Pure Science for the grant of a NATO Research Fellowship at the Department of Geology, Princeton University.

Professor H. D. Holland, Professor H. J. Greenwood and Mrs. Borcsik are gratefully acknowledged for their kind help and discussions during various stages in the work carried out at Princeton. Dr. R. A. RoвIE kindly brought the thermodynamic data on rutile and anatase to the writer's attention.

Mr. J. J. Schellink of the Vening Meinesz Laboratory was of great help during the experimental work at Utrecht.

\section{REFERENCES}

Dantelsson A. (1950) Das Calcit-Wollastonit Gleichgewicht. Geochim. Cosmochim. Acta 1, $50-69$.

Deer W. A., Howie R. A. and Zussman J. (1965) Rockforming Minerals, Vol IV. London.

HAREer R. I. and TutTle O. F. (1956) Experimental data on the $\mathbf{P}_{\mathrm{co}_{2}}-\mathbf{T}$ ourve for the roaction calcite + quartz $\leftrightharpoons$ wollastonite + carbondioxide. Amer. J. Sci. 254, 239-256.

JANAF (1960) Thermochemical Data. The Dow Chemical Company, Thermal Laboratory.

KARPOV I. K. (1966) Thermodynamic conditions of rutile and sphene equilibrium in limequartz bearing rocks of Mama-beds. Acad. Sci. U.S.S.R., Siberian Branch Geol. Geoph. 1, 125-128.

KELLEY K. K. (1960) Contribution to the data on thermochemical metallurgy. U.S. Bur. Mines, Bull. 584.

MaJumdar A. J. and Roy R. (1956) Fugacities and free energies of $\mathrm{CO}_{2}$ at high temperatures and pressures. Geochim. Cosmochim. Acta 10, 311-315.

MiLner H. B. (1962) Sedimentary Petrography, Vol. III: Principles and Applications. (4th edition) London, Murby.

RoвIE R. A. (1966) In: Handbook of Physical Constants (editor S. P. Clarke). Geol. Soc. Am., Mem. 97.

SNeLl F. D. (1959) Colorimetric Methods of Analysis. Van Nostrand.

Todd S. S. and K. K. Kelley (1956) Heat and free energy data for tricalcium dititanate, sphene, lithium metatitanate and zinc titanium spinol. U.S. Bur. of Mines, Rep. Invest. $5193,17 \mathrm{p}$. 